\title{
Magnetic Actuation of Flexible Microelectrode Arrays for Neural Activity Recordings
}

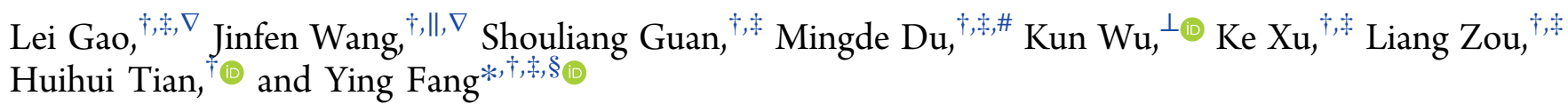

${ }^{\dagger}$ CAS Key Laboratory of Biomedical Effects of Nanomaterials and Nanosafety, CAS Center for Excellence in Nanoscience, National Center for Nanoscience and Technology, Beijing 100190, P. R. China

*University of Chinese Academy of Sciences, Beijing 100049, P. R. China

${ }^{\S}$ CAS Center for Excellence in Brain Science and Intelligence Technology, Chinese Academy of Sciences, Shanghai 200031, P. R. China

"State Key Laboratories of Transducer Technology, Chinese Academy of Sciences, Beijing 100190, P. R. China

${ }^{\perp}$ State Key Laboratory of High Temperature Gas Dynamics, Institute of Mechanics, Chinese Academy of Sciences, Beijing 100190, P. R. China

${ }^{\#}$ Department of Electronics and Nanoengineering, Aalto University, Espoo FI-00076, Finland

Supporting Information

ABSTRACT: Implantable microelectrodes that can be remotely actuated via external fields are promising tools to interface with biological systems at a high degree of precision. Here, we report the development of flexible magnetic microelectrodes (FM $\mu$ Es) that can be remotely actuated by magnetic fields. The $\mathrm{FM} \mu \mathrm{Es}$ consist of flexible microelectrodes integrated with dielectrically encapsulated FeNi (iron-nickel) alloy microactuators. Both magnetic torqueand force-driven actuation of the FM $\mu$ Es have been demonstrated. Nanoplatinumcoated $\mathrm{FM} \mu$ Es have been applied for in vivo recordings of neural activities from peripheral nerves and cerebral cortex of mice. Moreover, owing to their ultrasmall sizes and mechanical compliance with neural tissues, chronically implanted FM $\mu$ Es elicited greatly reduced neuronal cell loss in mouse brain compared to conventional stiff probes. The FM $\mu$ Es open up a variety of new opportunities for electrically interfacing with biological systems in a controlled and minimally invasive manner.

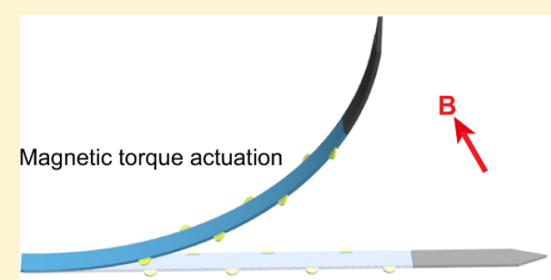

Magnetic force actuation

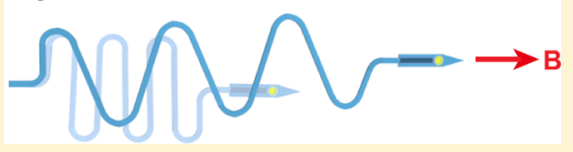

KEYWORDS: flexible microelectrode, magnetic actuation, nanoscale roughness, neural recording, inflammatory response

\begin{abstract}
T mplantable microelectrodes that transduce ionic signals to electronic signals are among the most widely applied tools for in vivo recordings of neural activities from peripheral and central nervous systems. ${ }^{1-3}$ Furthermore, implantable microelectrodes have been used clinically for the treatment of neurological disorders, such as Parkinson's disease. ${ }^{4}$ The importance of implantable microelectrodes has also been recognized in the development of peripheral nerve interfaces for prosthetic control. ${ }^{5}$ Conventional implantable microelectrodes are based on metals or silicon with elastic moduli in the range of $10^{2} \mathrm{GPa}$, whereas the elastic moduli of peripheral and central nervous systems are in the $\mathrm{MPa}$ to $\mathrm{kPa}$ range. ${ }^{6,7}$ The large mechanical mismatch between the implanted rigid microelectrodes and neural tissues results in tissue-electrode micromotion and chronic inflammatory responses. $^{8-11}$ Recently, flexible microelectrodes based on thin polymer substrates have been studied extensively due to their improved mechanical compliance to biological tissues. $^{12-15}$ Compared to rigid microelectrodes, flexible microelectrodes have demonstrated greatly reduced immune responses in chronic studies. ${ }^{14,15}$ However, the accurate in
\end{abstract}

vivo positioning of flexible microelectrodes presents an extremely challenging situation because of their susceptibility to buckling instability under in-plane compression. A variety of strategies, including syringe injection, ${ }^{14}$ removable insertion shuttles, ${ }^{12,15}$ polymer molds, ${ }^{16,17}$ and integrated microfluidic devices, ${ }^{18}$ have been used to temporarily increase the rigidity of flexible microelectrodes for in vivo positioning.

Remotely actuated microscale structures, such as micro- and nanoparticles, can interact with biological systems down to cellular scales and are of great importance for a wide variety of in vitro and in vivo applications, including the precise manipulation of single cells and the targeted delivery of drugs. ${ }^{19-21}$ Several actuation methods have been developed, including optical, ${ }^{22}$ electric, $^{23}$ thermal, $^{24}$ magnetic, ${ }^{21,25}$ and chemical fuel-driven actuation. ${ }^{26}$ Among these methods, magnetic actuation has been considered as one of the most

Received: August 7, 2019

Revised: September 24, 2019

Published: October 3, 2019 
a

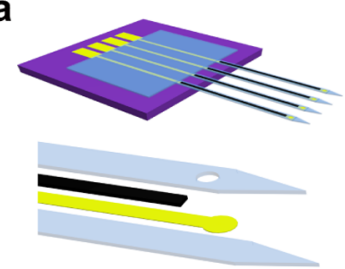

b

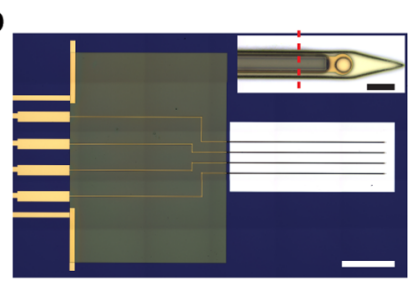

C

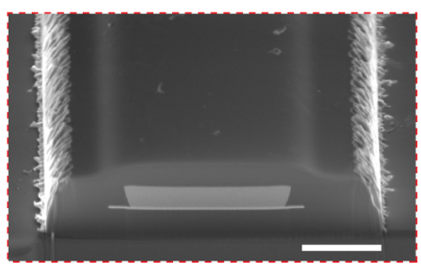

f

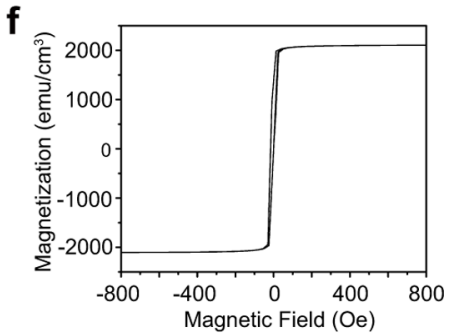

g
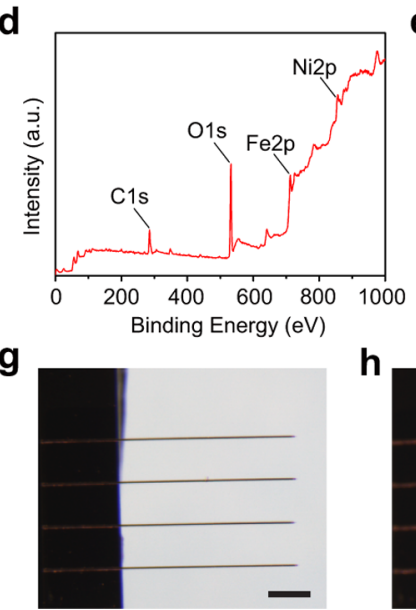

e

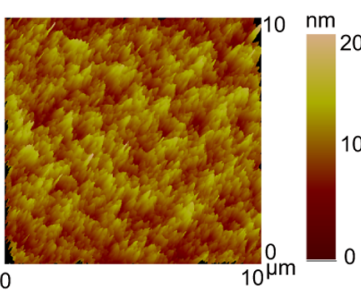

h

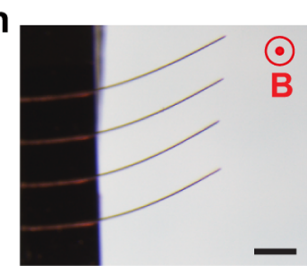

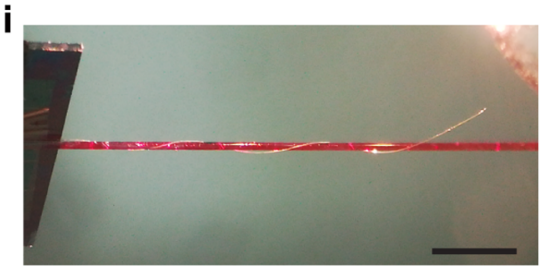

Figure 1. Magnetic torque-driven actuation of $\mathrm{FM} \mu \mathrm{Es}$. (a) Schematic of the layout of $\mathrm{FM} \mu \mathrm{Es}$. The $\mathrm{Si} / \mathrm{SiO}_{2}$ substrate, PI layers, Au conductive layer, and FeNi alloy layer are shown in purple, gray, yellow, and black color, respectively. (b) As-fabricated FM $\mu$ Es. Scale bar, $1 \mathrm{~mm}$. Inset, microphotoimage of an $\mathrm{FM} \mu \mathrm{E}$ with a 10- $\mu \mathrm{m}$-diameter recording site. Inset scale bar, $20 \mu \mathrm{m}$. (c) Cross-sectional SEM image of an FM $\mu \mathrm{E}$, indicated by the red dashed line in (b). Scale bar, $5 \mu \mathrm{m}$. (d) XPS of FeNi alloy layer. (e) AFM image of FeNi alloy layer. (f) Magnetization versus magnetic field $(\mathrm{M}-\mathrm{H})$ loop at room temperature. (g) Released FM $\mu$ Es in air. Scale bar, $500 \mu \mathrm{m}$. (h) Magnetic torque-driven actuation of FM $\mu$ Es by a rotating permanent magnet. The direction of magnetic field is perpendicular to the paper surface. Scale bar, 500 $\mu \mathrm{m}$. (i) A 15-mm-long FM $\mu \mathrm{E}$ was helically wound around a $200-\mu \mathrm{m}$-diameter optical fiber by a rotating permanent magnet. The optical fiber was dyed in red color. Scale bar, 2 mm.

promising means for in vivo applications because, unlike electric fields and light, magnetic fields are not attenuated or distorted by biological fluids and tissues. ${ }^{27}$ Therefore, magnetic fields can penetrate deep into the body without causing adverse health effects. In addition, compared to chemical fueldriven actuation, magnetic actuation does not use or produce harmful chemicals in vivo. Over the past two decades, a variety of microscale magnetic particles have been prepared and applied for targeted in vivo imaging and therapy. ${ }^{28,29}$ For example, magnetite magnetic nanoparticles can be remotely guided by external magnets to targeted areas for specific drug delivery, such as brain-targeted delivery of the anti-Alzheimer's drug tacrine. ${ }^{30}$ Helical magnetic micro- and nanoswimmers can be propelled in low Reynolds number fluids by rotating magnetic fields. ${ }^{31,32}$ Moreover, real-time, closed-loop navigation of magnetic microparticles has also been demonstrated using the propulsion gradient coils in a magnetic resonance imaging (MRI) scanner. ${ }^{33}$

The integration of sensing and actuating functions in microscale devices can give rise to innovative biological applications, including new biosensing platforms with the capability of remote manipulation amid complex biological environments. Here, we report $\mathrm{FM} \mu \mathrm{Es}$ that feature the integration of neural recording microelectrodes and magnetic microactuators. The FM $\mu$ Es can be remotely actuated by magnetic forces for in vivo interfacing with biological systems. Neural activity recordings from both mouse peripheral nerves and cerebral cortex have been demonstrated with the FM $\mu$ Es. Immunohistological studies have further confirmed that chronically implanted $\mathrm{FM} \mu \mathrm{Es}$ can form stable interfaces with the nervous systems.
Figure 1a shows the schematic of $\mathrm{FM} \mu \mathrm{Es}$ consisting of recording microelectrodes and magnetic microactuators. The $\mathrm{FM} \mu \mathrm{Es}$ were fabricated on the $\mathrm{Si} / \mathrm{SiO}_{2}$ substrates with patterned sacrificial aluminum (Al) layers (Figure S1). As shown in Figure $1 b$, the microelectrodes are sandwiched between $2-\mu \mathrm{m}$-thick polyimide (PI) layers (except the recording sites and bonding pads). To achieve remote magnetic actuation, FeNi alloy microactuators were selectively formed at the end-points of the microelectrodes by electrodeposition and subsequently encapsulated with PI layers to protect them from in vivo degradation. FeNi alloy was chosen because of its high saturation magnetization and low coercivity. $^{34,35}$ Figure 1c shows a focused ion beam (FIB)prepared cross-sectional scanning electron microscopy (SEM) image of a $2-\mu \mathrm{m}$-thick and $10-\mu \mathrm{m}$-wide $\mathrm{FeNi}$ alloy layer that has been completely encapsulated by PI.

Next, we characterized the structural and magnetic properties of the electrodeposited FeNi alloy layers. The surface chemical composition of the FeNi alloy was studied by X-ray photoelectron spectroscopy (XPS) (Figures 1d and S2a,b). The peaks of $\mathrm{Fe} 2 \mathrm{p}_{3 / 2}$ and $\mathrm{Fe} 2 \mathrm{p}_{1 / 2}$ are located at 711.4 and $724.6 \mathrm{eV}$ (Figure S2a), respectively. ${ }^{36}$ The peaks at 856.0 and $873.7 \mathrm{eV}$ are attributed to $\mathrm{Ni} 2 \mathrm{p}_{3 / 2}$ and $\mathrm{Ni} 2 \mathrm{p}_{1 / 2}$ (Figure S2b), respectively. The surface $\mathrm{Fe} / \mathrm{Ni}$ atomic ratio was calculated to be 47.7/52.3 from the XPS spectra. Figure S2c shows the X-ray diffraction (XRD) pattern recorded from the FeNi alloy. The peaks located at $43.88^{\circ}$ and $50.77^{\circ}$ were assigned to diffraction from the (111) and (200) planes, respectively, of a facecentered cubic $(\mathrm{fcc})$ lattice with a unit cell size of $0.357 \mathrm{~nm} .^{35}$ The surface morphology of the FeNi alloy was characterized with atomic force microscopy (AFM) (Figure 1e), which 
a

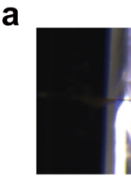

C

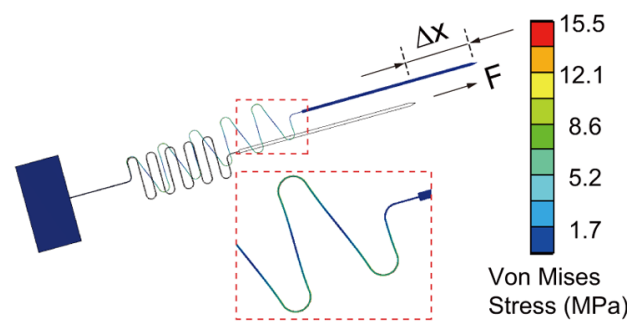

b

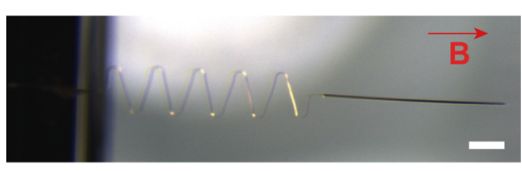

d

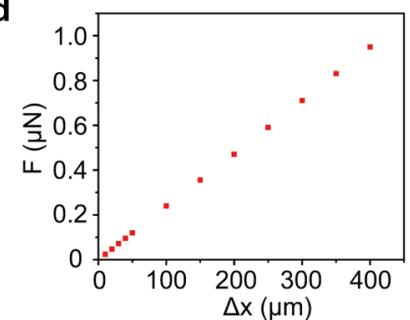

Figure 2. Magnetic force-driven actuation of $\mathrm{FM} \mu \mathrm{E}$. (a) Microphotoimage of an FM $\mu \mathrm{E}$ consisting of a magnetic head and a stretchable serpentine microspring. Scale bar, $200 \mu \mathrm{m}$. (b) Microphotoimage showing that the magnetic force stretched the microspring by up to $400 \mu \mathrm{m}$. The permanent magnet was placed at a distance of ca. $2 \mathrm{~mm}$, and the red arrow indicates the direction of magnetic field. Scale bar, $200 \mu \mathrm{m}$. (c) Mechanical simulation of the stress distribution on a stretched FM $\mu$ E. (d) Numerical value of the force $(F)$ as a function of the displacement $(\Delta x)$.

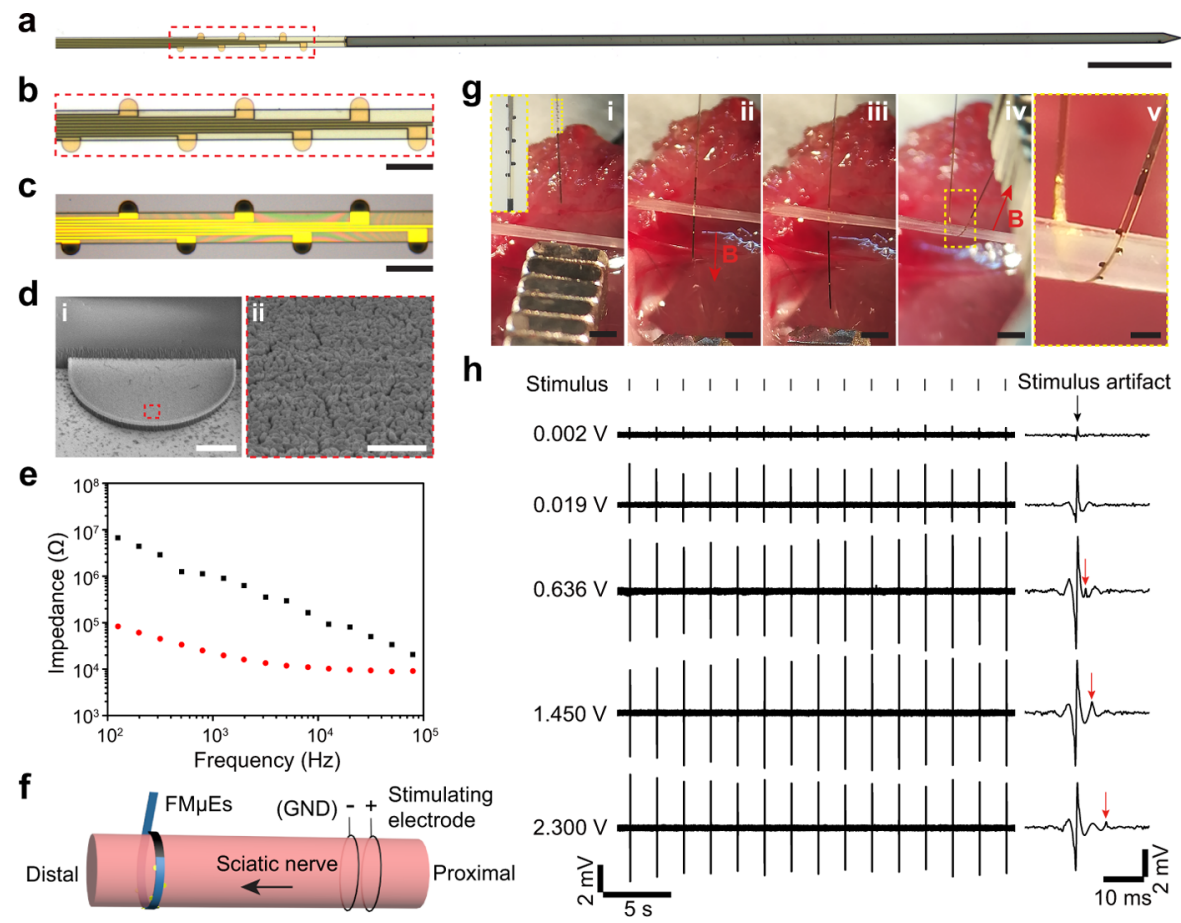

Figure 3. In vivo neural activity recording from the sciatic nerve. (a) FM $\mu \mathrm{E}$ array for neural activity recordings from mouse sciatic nerve. Scale bar, $500 \mu \mathrm{m}$. (b) Zoom-in view of the recording sites as marked by the red dashed box in (a). Scale bar, $100 \mu \mathrm{m}$. (c) Recording sites after nanoplatinum deposition. Scale bar, $100 \mu \mathrm{m}$. (d) (i) SEM image of a recording site coated with nanoplatinum. Scale bar, $10 \mu \mathrm{m}$. (ii) Zoom-in view of the nanoplatinum as marked by the red dashed box in (i). Scale bar, $1 \mu \mathrm{m}$. (e) Electrochemical impedance spectroscopy (EIS) of the FM $\mu$ E array before (black squares) and after (red dots) modification with nanoplatinum, respectively. (f) Schematic of the setup for sciatic nerve recordings. (g) Remote magnetic actuation of the $\mathrm{FM} \mu \mathrm{E}$ array to interface with the sciatic nerve, and the red arrow indicates the direction of magnetic field. Scale bars, $1 \mathrm{~mm}$ in (i-iv) and $200 \mu \mathrm{m}$ in (v). (h) Electrical recordings of stimulated CAPs (indicated by the red arrows). The signals were band-pass filtered at $250-2000 \mathrm{~Hz}$. The frequency and duration of the stimulus voltage were $0.5 \mathrm{~Hz}$ and $0.2 \mathrm{~ms}$, respectively.

revealed a relatively small root-mean-square (RMS) roughness of $\sim 20 \mathrm{~nm}$. The magnetic properties of the FeNi alloy microactuators in the $\mathrm{FM} \mu \mathrm{Es}$ were studied by measuring the magnetization versus magnetic field $(\mathrm{M}-\mathrm{H})$ loop at room temperature. As shown in the hysteresis loop in Figure 1f, the electrodeposited FeNi alloy microactuators exhibited high saturation magnetization of $2070 \mathrm{emu} / \mathrm{cm}^{3}$ and low coercivity of below 20 Oe. $^{37}$

The good soft magnetic properties of $\mathrm{FM} \mu \mathrm{Es}$ make them suitable for magnetic actuation applications. The magnetic torque, $\overrightarrow{\tau_{m}}$, and magnetic force, $\overrightarrow{F_{m}}$, exerted on a magnetized structure can be expressed as follows: ${ }^{21,27}$

$$
\overrightarrow{\tau_{m}}=V_{m} \vec{M} \times \vec{B}
$$

and

$$
\overrightarrow{F_{m}}=V_{m}(\vec{M} \cdot \nabla) \vec{B}
$$

where $\vec{M}$ is the magnetization, $V_{m}$ is the volume, and $\vec{B}$ is the magnetic flux density. From the relationship, we can see that the magnetic torque is proportional to the magnetic field and 


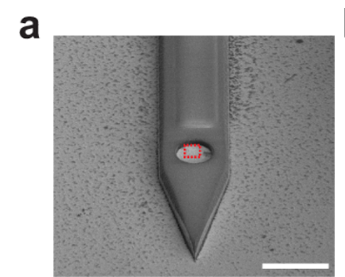

e

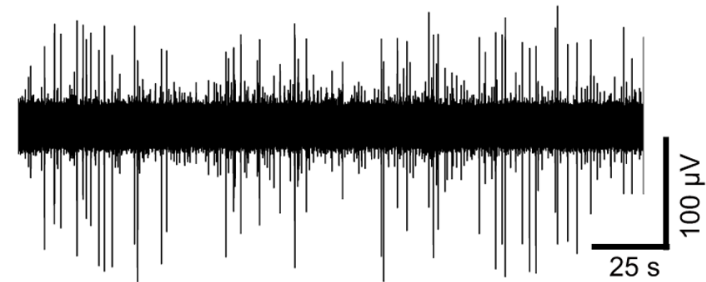

g

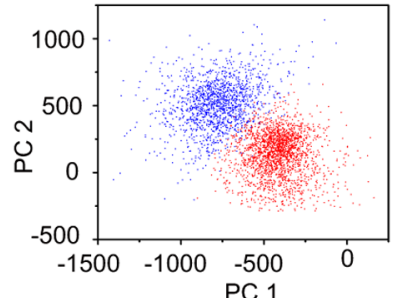

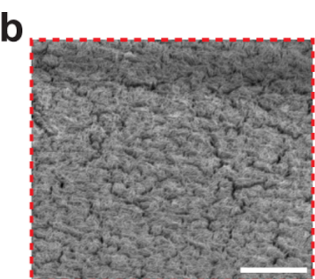

(n)

h

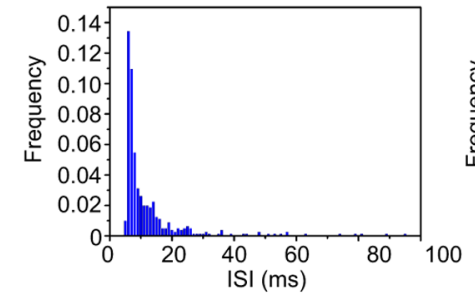

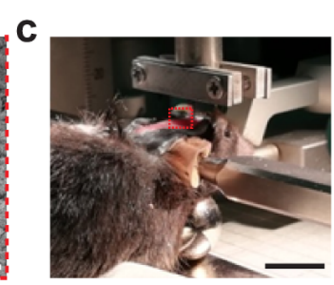

f i
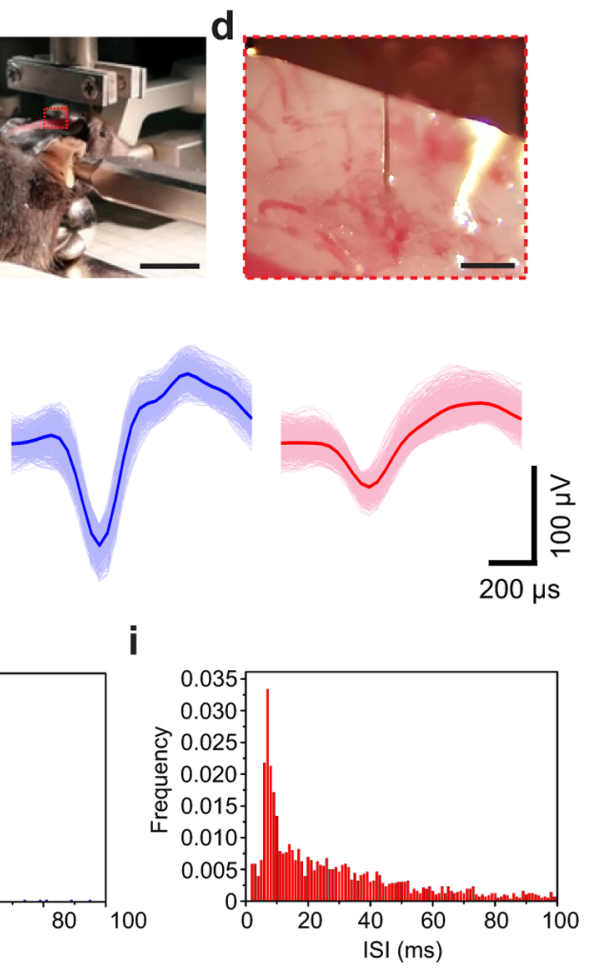

Figure 4. In vivo neural activity recordings from cerebral cortex. (a) SEM of an FM $\mu$ E. Scale bar, $20 \mu \mathrm{m}$. (b) Micromorphology of the nanoplatinum coating as marked by the red dashed box in (a). Scale bar, $1 \mu \mathrm{m}$. (c) Implanted FM $\mu \mathrm{E}$ in mouse cerebral cortex. Scale bar, $10 \mathrm{~mm}$. (d) Zoom-in view of the implanted $\mathrm{FM} \mu \mathrm{E}$ as marked by the red dashed box in (c). Scale bar, $200 \mu \mathrm{m}$. (e) Representative AP trace recorded by an FM $\mu$ E from M2 cortex. (f) Aligned and mean spike waveforms of sortable spike 1 (blue) and spike 2 (red). (g) Principal component analysis (PCA) showing two distinct clusters. (h) Interspike-interval (ISI) histogram of spike 1. (i) ISI histogram of spike 2.

that the magnetic force is proportional to the gradient of the magnetic field. We first investigated the magnetic torquedriven actuation of $\mathrm{FM} \mu \mathrm{Es}$ by using a rotating $\mathrm{NdFeB}$ permanent magnet. A wet etching process was carried out to remove the sacrificial $\mathrm{Al}$ layers and release the $\mathrm{FM} \mu \mathrm{Es}$. The magnet was placed ca. $1 \mathrm{~cm}$ apart from the $\mathrm{FM} \mu$ Es. The magnetic flux density around the magnetic heads of $\mathrm{FM} \mu \mathrm{Es}$ was measured as $\sim 0.05 \mathrm{~T}$ (Figure S3). Figures $1 \mathrm{~g}$,h illustrate the magnetic torque-induced bending movements of FM $\mu$ Es by the rotating magnet. Note that only flexible microelectrodes integrated with magnetic microactuators were selectively actuated by magnetic torque (Figure S4). Figure 1i shows a 4- $\mu \mathrm{m}$-thick and $20-\mu \mathrm{m}$-wide $\mathrm{FM} \mu \mathrm{E}$ that was helically wound around a $200-\mu \mathrm{m}$-diameter optical fiber by using a permanent magnet. These results confirm that remote magnetic actuation can allow facile and controllable positioning of flexible and ultrasmall microelectrodes.

Next, we examined force-driven actuation of FM $\mu$ Es by magnetic gradients. In order to quantitatively characterize the magnitude of the exerted magnetic forces, the magnetic heads of $\mathrm{FM} \mu \mathrm{Es}$ were implemented with stretchable serpentine microsprings (Figure S5). After being released from the $\mathrm{Si}$ / $\mathrm{SiO}_{2}$ substrate, an $\mathrm{FM} \mu \mathrm{E}$ was exposed to the magnetic field gradient of a permanent magnet at a distance of ca. $2 \mathrm{~mm}$. As shown in Figure 2a,b, the magnetic force dragged the magnetic head of $\mathrm{FM} \mu \mathrm{E}$ toward the local maximum of field and stretched the microspring by up to $400 \mu \mathrm{m}$. We carried out three-dimensional finite element analysis (FEA) to simulate the stretching process of $\mathrm{FM} \mu \mathrm{E}$ by magnetic forces. The initial configuration of $\mathrm{FM} \mu \mathrm{E}$ in the FEA was based on the structure of the device shown in Figure 2a. The base plate of FM $\mu \mathrm{E}$ was fixed in the simulations, and the end-point of $\mathrm{FM} \mu \mathrm{E}$ was subjected to a prescribed longitudinal displacement, $\Delta x$. Figure $2 \mathrm{c}$ shows the stress distribution of $\mathrm{FM} \mu \mathrm{E}$ subjected to an elongation of $\Delta x=400 \mu \mathrm{m}$, which reveals that the stress concentrations are mainly located on the microspring. We then calculated the numerical value of the force, $F$, exerted on the tip of $\mathrm{FM} \mu \mathrm{E}$ at various displacements. As shown in Figure 2d, the force is linearly proportional to the displacement of the microspring, consistent with Hooke's law. The 4- $\mu$ m-thick and $3.5-\mu \mathrm{m}$-wide microspring has a force constant of $2.4 \mathrm{mN} / \mathrm{m}$, and the magnetic force exerted on the tip of $\mathrm{FM} \mu \mathrm{E}$ in Figure $2 \mathrm{a}$ was thus estimated to be ca. $1 \mu \mathrm{N}$. This force value is comparable to contraction forces of single cardiac myocytes. $^{38,39}$ These results indicate that remote magnetic actuation of $\mathrm{FM} \mu \mathrm{Es}$ may be potentially used for wellcontrolled mechanical manipulation of biological systems.

Implantable devices that interface with the peripheral nervous system have shown promise for restoring sensory and motor functions in patients who experience neurological injuries or amputations. ${ }^{5}$ Over the past decades, intensive research efforts have been focused on reducing the structural and mechanical mismatches between implanted electrodes and peripheral nerve tissues. ${ }^{40}$ In particular, flexible peripheral nerve electrodes ${ }^{3,41,42}$ have shown improved biocompatibility compared to stiff electrodes. However, the accurate in vivo positioning of flexible peripheral nerve electrodes has been challenging. In contrast, the remote magnetic actuation of our $\mathrm{FM} \mu$ Es allows them to interface with the peripheral nerves in a controllable manner. Figure $3 \mathrm{a}, \mathrm{b}$ shows a $4-\mu \mathrm{m}$-thick and 65 $\mu \mathrm{m}$-wide $\mathrm{FM} \mu \mathrm{E}$ array consisting of seven semicircular archshaped recording sites and one magnetic microactuator. To the 


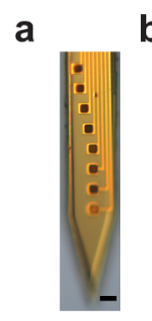

C

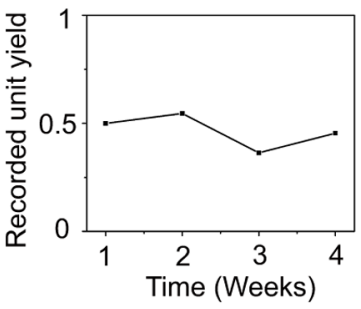

f

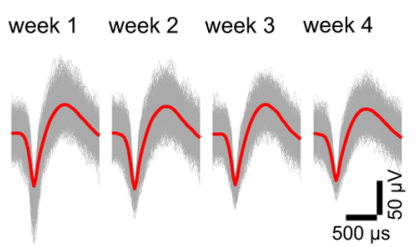

b

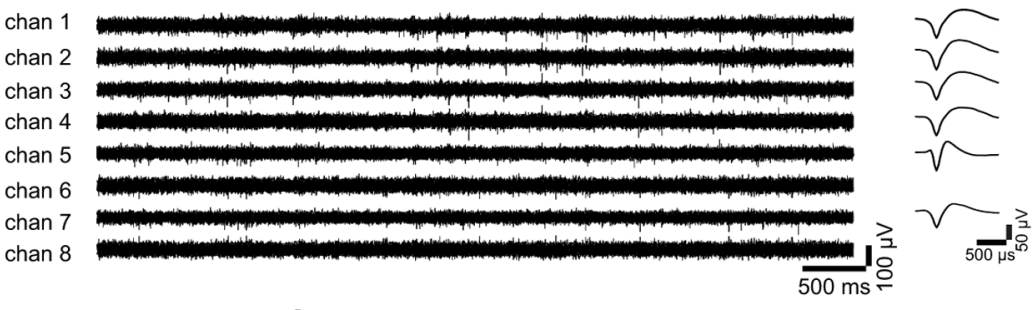

d

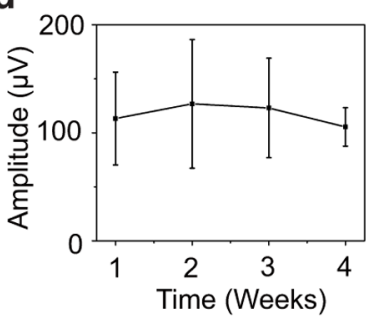

g

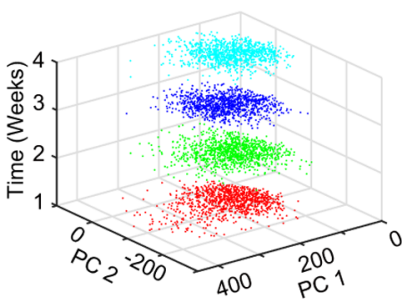

e

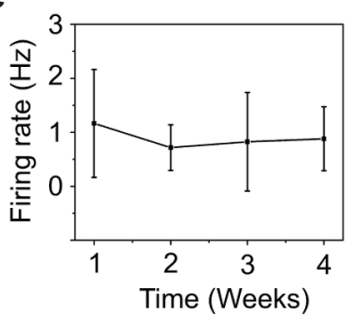

h

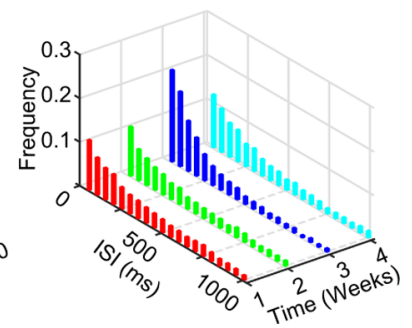

Figure 5. In vivo chronic recordings from MO cortex. (a) Optical image of an 8-channel FM $\mu \mathrm{E}$ array. Scale bar, $20 \mu \mathrm{m}$. (b) Representative 8channel AP traces recorded by the $\mathrm{FM} \mu \mathrm{E}$ array from MO cortex. (c) Recorded unit yield as a function of time. (d,e) Average spike amplitude and firing rates of all recorded units during the 4-week recording. Error bars represent the SD around the mean. (f) Aligned and averaged spike waveforms of a representative single unit recorded by an FM $\mu$ E from week-1 to week-4 (>1000 waveforms per average). (g) PCA of all waveforms in (f). (h) Time evolution of ISI histograms for the single unit in (f). Bin size, $50 \mathrm{~ms}$.

best of our knowledge, these are the smallest peripheral nerve microelectrodes ever reported. Before neural recording, platinum was electrodeposited on the recording sites (Figure $3 c$ ). The nanoscale roughness of the platinum films effectively increased the active surface areas of the microelectrodes (Figure 3d). As a result, the impedance of the microelectrodes (at $1 \mathrm{kHz}$ ) decreased by a factor of $\sim 40$ (Figure $3 \mathrm{e}$ ), which can effectively reduce the thermal noise during neural recordings. ${ }^{43}$ The $\mathrm{FM} \mu \mathrm{E}$ array was then controllably wound around the distal trunk of a mouse sciatic nerve, with a diameter of only $\sim 400 \mu \mathrm{m}$, for desired turns by a permanent magnet placed ca. $3 \mathrm{~mm}$ away from the $\mathrm{FM} \mu \mathrm{E}$ array (Figures 3f,g and S6). Evoked neural activities were recorded by the $\mathrm{FM} \mu \mathrm{E}$ array when monophasic square-wave voltage pulses were applied on the proximal trunk at $\sim 2 \mathrm{~mm}$ distance (Figure 3f,g). Former studies have shown that the nerve stimulus threshold is inversely related to the diameter of the motor axons. ${ }^{44}$ Thus, large-diameter nerve fibers that are innervated by large motor neurons are the first to be recruited during electrical stimulation. $^{45}$ As shown in Figures $3 \mathrm{~h}$ and S7, the first compound action potential (CAP) from a fast and largediameter nerve fiber was recorded by the $\mathrm{FM} \mu \mathrm{E}$ array at a stimulus voltage of $0.6 \mathrm{~V}$. The CAP propagated from the stimulating electrode to the $\mathrm{FM} \mu \mathrm{E}$ array with a conduction latency of $2.5 \pm 0.5 \mathrm{~ms}$. When the stimulus voltage was increased to $2.3 \mathrm{~V}$, the CAP from a slow and small-diameter nerve fiber was recorded by the $\mathrm{FM} \mu \mathrm{E}$ array, with a conduction latency of $6.7 \pm 0.4 \mathrm{~ms}$. Moreover, Figure S8 shows representative multichannel recordings of evoked CAPs in the mouse sciatic nerve. These results demonstrate that the $\mathrm{FM} \mu \mathrm{E}$ array can serve as a facile tool for peripheral nerve interfacing and electrical recordings.

Next, we implanted FM $\mu$ Es into the secondary motor (M2) cortex of mouse brain for intracortical single-unit recordings. During implantation, a permanent magnet was placed underneath the mouse jaw to adjust the implantation angle of $\mathrm{FM} \mu \mathrm{Es}$. The distance between the magnet and the $\mathrm{FM} \mu \mathrm{E}$ was about $12 \mathrm{~mm}$, and the implantation angle of the $\mathrm{FM} \mu \mathrm{E}$ was adjusted to be normal to the mouse brain surface. It should be noted that the magnetic gradient of the permanent magnet decreases rapidly with increased distance, and the magnetic forces on the $\mathrm{FM} \mu$ Es were not large enough for tissue penetration. ${ }^{15}$ Before implantation, the recording sites of $\mathrm{FM} \mu \mathrm{Es}$ were modified with nanorough platinum films to reduce their impedance and thermal noise (Figures $4 a, b$ and S9). The FM $\mu$ Es were then inserted into the mouse cortex by moving up and down repeatedly until they punctured the tissue (Figures 4c,d and S10). Figure 4e shows a representative action potential (AP) trace recorded by an $\mathrm{FM} \mu \mathrm{E}$. Spike sorting revealed two well-separated neuronal units $\left(L_{\text {ratio }}=\right.$ 0.039 and isolation distance $=47)$ (Figure $4 \mathrm{f}-\mathrm{i}){ }^{46,47}$ Moreover, both neurons fired stably during the $3 \mathrm{~h}$ recording period, which indicated that they stayed in close proximity to the microelectrode during recording. ${ }^{2}$

We next implanted 8-channel $\mathrm{FM} \mu \mathrm{E}$ arrays into the medial orbital (MO) cortex of mice $(n=4)$ and evaluated their recording stability in a 4-week period. Before implantation, the recording sites of $\mathrm{FM} \mu \mathrm{E}$ arrays were modified with nanorough 
a

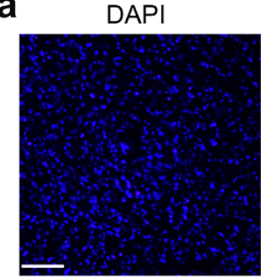

b

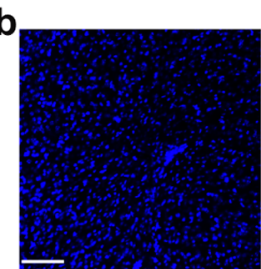

C

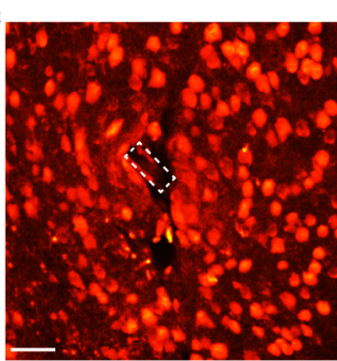

NeuN
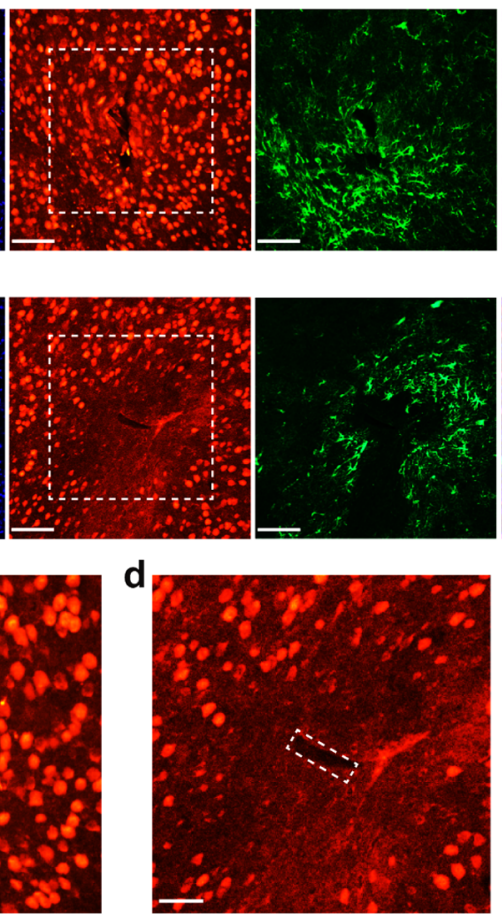

GFAP

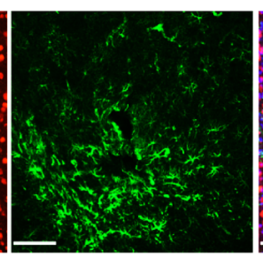

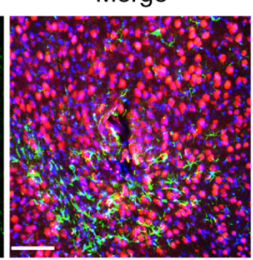
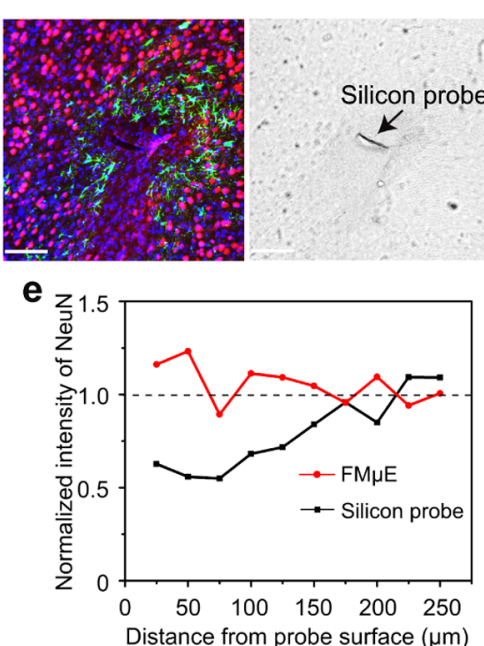

Figure 6. Chronic immune responses to implanted $\mathrm{FM} \mu \mathrm{E}$ probe (a) and silicon probe (b). The 100- $\mu$ m-thick horizontal brain slices were labeled for nuclei (DAPI, blue), neurons (NeuN, red), and astrocytes (GFAP, green), respectively. Scale bar, $100 \mu \mathrm{m}$. (c,d) Zoom-in view of the staining images for neurons as marked by the white dashed boxes in (a) and (b), respectively. The edges of the FM $\mu \mathrm{E}$ and silicon probe were highlighted by white dashed boxes. Scale bar, $50 \mu \mathrm{m}$. (e) Fluorescence intensity of NeuN normalized against background values was plotted against the distance from surfaces of the $\mathrm{FM} \mu \mathrm{E}$ and silicon probe, respectively.

platinum films (Figure 5a). Figure $5 \mathrm{~b}$ shows representative AP traces recorded by an implanted $\mathrm{FM} \mu \mathrm{E}$ array from the $\mathrm{MO}$ cortex of a mouse (M01). Single-unit activities were recorded by 6 of the 8 microelectrodes in the FM $\mu$ E array. Overall, 812 units were recorded from $22 \mathrm{FM} \mu$ Es at a single recording day over the 4-week period, corresponding to a unit yield of 0.4-0.5 (Figure 5c). Moreover, the average spike amplitude and firing rates of the recorded units remained relatively stable (Figure 5d,e). Figure 5f shows the averaged waveforms of a representative unit recorded by an $\mathrm{FM} \mu \mathrm{E}$ (M04) from week-1 to week-4. The shape similarity between the averaged waveforms was evaluated by calculating the cross-correlation coefficient. $^{48}$ As shown in Table S1, high waveform similarity was observed during the 4-week recording period. Besides, PCA yielded overlapping clusters, and the ISI histograms showed similar distribution patterns from week-1 to week-4 (Figure $5 \mathrm{~g}, \mathrm{~h}$ ). These results suggest that the recorded singleunit activities might be from the same neuron. ${ }^{49,50}$

Lastly, we evaluated the in vivo chronic biocompatibility of $\mathrm{FM} \mu \mathrm{Es}$ in mouse brain. For comparison, both FM $\mu \mathrm{Es}$ and conventional silicon probes were implanted into mouse brain. Chronic tissue responses to the implanted probes were evaluated after 5 and 9 weeks postimplantation. Figure $6 a, b$ shows representative immunohistochemical staining results of brain slices implanted with an $\mathrm{FM} \mu \mathrm{E}$ and a silicon probe, respectively, at 5 weeks postimplantation. Glial fibrillary acidic protein (GFAP), ${ }^{51}$ an intermediate filament of astrocytes, shows increased expression around both the $\mathrm{FM} \mu \mathrm{E}$ and the silicon probe at 5 weeks postimplantation. The astrocyte activation extended out $\sim 200 \mu \mathrm{m}$ around the implantation sites and might be related to the initial wound healing responses from the insertion injury. Notably, the $\mathrm{FM} \mu \mathrm{E}$ and the silicon probe elicited distinctly different neuronal cell responses (Figure $6 \mathrm{c}-\mathrm{e}$ ). As shown in Figure $6 \mathrm{~d}$, a clear neuron "kill zone" of 100-200 $\mu \mathrm{m}$ appeared around the silicon probe at 5 weeks postimplantation. This is consistent with former studies showing that the mechanical mismatch and micromotion between stiff silicon probes and neural tissues can induce inflammatory responses and neuronal cell loss around the implantation sites. ${ }^{9,11}$ However, minimal neuronal cell loss was observed around the $\mathrm{FM} \mu \mathrm{E}$ at 5 weeks postimplantation (Figure 6c). We further evaluated the brain tissue response to an $\mathrm{FM} \mu \mathrm{E}$ at 9 weeks postimplantation (Figure S11). No obvious decrease in the density of neuronal cells was observed around the FM $\mu \mathrm{E}$. Moreover, the density of GFAP-positive astrocytes around the $\mathrm{FM} \mu \mathrm{E}$ has reduced to normal levels at 9 weeks postimplantation. These results are consistent with the immunohistochemical results of previously reported flexible probes, ${ }^{52,53}$ confirming that FM $\mu$ Es can form chronically stable interfaces with the central nervous system.

In conclusion, we have fabricated $\mathrm{FM} \mu \mathrm{Es}$ that can be remotely actuated by magnetic fields. The FM $\mu$ Es have been demonstrated for in vivo recordings of neural activities from both peripheral nerves and cerebral cortex. Immunohistochemical staining results showed that the chronically implanted $\mathrm{FM} \mu$ Es elicited minimal neuronal cell loss in mouse brain. The $\mathrm{FM} \mu \mathrm{Es}$, therefore, show great promise for the electrical interfacing with biological systems in a minimally invasive manner. The permanent magnets used here, however, are limited in both workspace and degrees of freedom (DoF). Future work will involve the implementation of electromagnetic actuation systems with a large workspace and high 
DoF, as well as high-frequency alternating fields for the controllable navigation of FM $\mu$ Es amid complex biological systems. $^{52-58}$ In addition, MRI systems are routinely used in both basic and clinical neuroscience; thus, future studies are needed to evaluate the biological safety of implanted FM $\mu$ Es for use in MRI. Nevertheless, the magnetic actuation of ultrasmall $\mathrm{FM} \mu$ Es provides a means to induce micro-Newton forces from a remote distance, which may open up new possibilities for the in vitro and in vivo mechanical manipulation and electrical probing of neural circuits.

\section{ASSOCIATED CONTENT}

\section{S Supporting Information}

The Supporting Information is available free of charge on the ACS Publications website at DOI: 10.1021/acs.nanolett.9b03232.

Detailed description of experimental methods and additional figures (PDF)

\section{AUTHOR INFORMATION}

\section{Corresponding Author}

*E-mail: fangy@nanoctr.cn.

ORCID

Kun Wu: 0000-0002-1626-396X

Huihui Tian: 0000-0002-9015-4817

Ying Fang: 0000-0003-2965-7287

\section{Author Contributions}

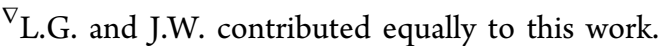

\section{Notes}

The authors declare no competing financial interest.

\section{ACKNOWLEDGMENTS}

We thank the Fabrication Lab at NCNST for the microfabrication facilities and support. We thank Dr. Kai Zhong for helpful discussions on magnetic field analyses. Y.F. acknowledges the support from the Strategic Priority Research Program of the Chinese Academy of Sciences (Grant No. XDB32030100), the National Natural Science Foundation of China (Nos. 21790393 and 21673057), and the Frontier Research Program of the Chinese Academy of Sciences (QYZDB-SSW-SLH044).

\section{REFERENCES}

(1) Donoghue, J. P. Nat. Neurosci. 2002, 5, 1085-1088.

(2) Buzsáki, G.; Anastassiou, C. A.; Koch, C. Nat. Rev. Neurosci. 2012, 13, 407-420.

(3) Rodríguez, F. J.; Ceballos, D.; Schüttler, M.; Valero, A.; Valderrama, E.; Stieglitz, T.; Navarro, X. J. Neurosci. Methods 2000, $98,105-118$.

(4) Miocinovic, S.; Somayajula, S.; Chitnis, S.; Vitek, J. L. JAMA Neurol. 2013, 70, 163-171.

(5) Navarro, X.; Krueger, T. B.; Lago, N.; Micera, S.; Stieglitz, T.; Dario, P. J. Peripher. Nerv. Syst. 2005, 10, 229-258.

(6) Rydevik, B. L.; Kwan, M. K.; Myers, R. R.; Brown, R. A.; Triggs, K. J.; Woo, S. L-Y.; Garfin, S. R. J. Orthop. Res. 1990, 8, 694-701.

(7) Green, M. A.; Bilston, L. E.; Sinkus, R. NMR Biomed. 2008, 21, $755-764$.

(8) Gilletti, A.; Muthuswamy, J. J. Neural Eng. 2006, 3, 189-195.

(9) Biran, R.; Martin, D. C.; Tresco, P. A. Exp. Neurol. 2005, 195, $115-126$.

(10) Kozai, T. D. Y.; Jaquins-Gerstl, A. S.; Vazquez, A. L.; Michael, A. C.; Cui, X. T. ACS Chem. Neurosci. 2015, 6, 48-67.
(11) Polikov, V. S.; Tresco, P. A.; Reichert, W. M. J. Neurosci. Methods 2005, 148, 1-18.

(12) Kim, T.-i.; McCall, J. G.; Jung, Y. H.; Huang, X.; Siuda, E. R.; Li, Y.; Song, J.; Song, Y. M.; Pao, H. A.; Kim, R.-H.; Lu, C.; Lee, S. D.; Song, I.-S.; Shin, G.; Al-Hasani, R.; Kim, S.; Tan, M. P.; Huang, Y.; Omenetto, F. G.; Rogers, J. A.; Bruchas, M. R. Science 2013, 340, 211-216.

(13) Khodagholy, D.; Gelinas, J. N.; Thesen, T.; Doyle, W.; Devinsky, O.; Malliaras, G. G.; Buzsáki, G. Nat. Neurosci. 2015, 18, 310-315.

(14) Liu, J.; Fu, T.-M.; Cheng, Z.; Hong, G.; Zhou, T.; Jin, L.; Duvvuri, M.; Jiang, Z.; Kruskal, P.; Xie, C.; Suo, Z.; Fang, Y.; Lieber, C. M. Nat. Nanotechnol. 2015, 10, 629-636.

(15) Luan, L.; Wei, X.; Zhao, Z.; Siegel, J. J.; Potnis, O.; Tuppen, C. A.; Lin, S.; Kazmi, S.; Fowler, R. A.; Holloway, S.; Dunn, A. K.; Chitwood, R. A.; Xie, C. Sci. Adv. 2017, 3, No. e1601966.

(16) Kozai, T. D. Y.; Gugel, Z.; Li, X.; Gilgunn, P. J.; Khilwani, R.; Ozdoganlar, O. B.; Fedder, G. K.; Weber, D. J.; Cui, X. T. Biomaterials 2014, 35, 9255-9268.

(17) Xiang, Z.; Yen, S.-C.; Xue, N.; Sun, T.; Tsang, W. M.; Zhang, S.; Liao, L.-D.; Thakor, N. V.; Lee, C. J. Micromech. Microeng. 2014, 24, No. 065015.

(18) Vitale, F.; Vercosa, D. G.; Rodriguez, A. V.; Pamulapati, S. S.; Seibt, F.; Lewis, E.; Yan, J. S.; Badhiwala, K.; Adnan, M.; RoyerCarfagni, G.; Beierlein, M.; Kemere, C.; Pasquali, M.; Robinson, J. T. Nano Lett. 2018, 18, 326-335.

(19) Nelson, B. J.; Kaliakatsos, I. K.; Abbott, J. J. Annu. Rev. Biomed. Eng. 2010, 12, 55-85.

(20) Dobson, J. Nat. Nanotechnol. 2008, 3, 139-143.

(21) Peyer, K. E.; Zhang, L.; Nelson, B. J. Nanoscale 2013, 5, 12591272.

(22) Eichenfield, M.; Michael, C. P.; Perahia, R.; Painter, O. Nat. Photonics 2007, 1, 416-422.

(23) Luo, X.; Mather, P. T. Soft Matter 2010, 6, 2146-2149.

(24) Moulton, T.; Ananthasuresh, G. K. Sens. Actuators, A 2001, 90, $38-48$.

(25) Choi, H.; Choi, J.; Jang, G.; Park, J.-o.; Park, S. Smart Mater. Struct. 2009, 18, No. 055007.

(26) Sánchez, S.; Pumera, M. Chem. - Asian J. 2009, 4, 1402-1410.

(27) Xu, T.; Yu, J.; Yan, X.; Choi, H.; Zhang, L. Micromachines 2015, 6, 1346-1364.

(28) Polyak, B.; Fishbein, I.; Chorny, M.; Alferiev, I.; Williams, D.; Yellen, B.; Friedman, G.; Levy, R. J. Proc. Natl. Acad. Sci. U. S. A. 2008, 105, 698-703.

(29) Lübbe, A. S.; Alexiou, C.; Bergemann, C. J. Surg. Res. 2001, 95, 200-206.

(30) Wilson, B.; Samanta, M. K.; Santhi, K.; Sampath Kumar, K. P.; Ramasamy, M.; Suresh, B. J. Neurosci. Methods 2009, 177, 427-433.

(31) Vach, P. J.; Brun, N.; Bennet, M.; Bertinetti, L.; Widdrat, M.; Baumgartner, J.; Klumpp, S.; Fratzl, P.; Faivre, D. Nano Lett. 2013, 13, 5373-5378.

(32) Peyer, K. E.; Tottori, S.; Qiu, F.; Zhang, L.; Nelson, B. J. Chem. - Eur. J. 2013, 19, 28-38.

(33) Mathieu, J.-B.; Martel, S. Biomed. Microdevices 2007, 9, 801808.

(34) Koohkan, R.; Sharafi, S.; Shokrollahi, H.; Janghorban, K. J. Magn. Magn. Mater. 2008, 320, 1089-1094.

(35) Cao, Y.; Wei, G. Y.; Ge, H. L.; Meng, X. F. Surf. Eng. 2014, 30, 97-101.

(36) Zhou, L.; Wen, M.; Wu, Q.; Wu, D. Dalton Trans. 2014, 43, 7924-7929.

(37) Su, X.; Qiang, C. Bull. Mater. Sci. 2012, 35, 183-189.

(38) Kajzar, A.; Cesa, C. M.; Kirchgeßner, N.; Hoffmann, B.; Merkel, R. Biophys. J. 2008, 94, 1854-1866.

(39) Yasuda, S.-I.; Sugiura, S.; Kobayakawa, N.; Fujita, H.; Yamashita, H.; Katoh, K.; Saeki, Y.; Kaneko, H.; Suda, Y.; Nagai, R.; Sugi, H. Am. J. Physiol. Heart Circ. Physiol. 2001, 281, H1442H1446. 
(40) Christensen, M. B.; Pearce, S. M.; Ledbetter, N. M.; Warren, D. J.; Clark, G. A.; Tresco, P. A. Acta Biomater. 2014, 10, 4650-4660.

(41) Wurth, S.; Capogrosso, M.; Raspopovic, S.; Gandar, J.; Federici, G.; Kinany, N.; Cutrone, A.; Piersigilli, A.; Pavlova, N.; Guiet, R.; Taverni, G.; Rigosa, J.; Shkorbatova, P.; Navarro, X.; Barraud, Q.; Courtine, G.; Micera, S. Biomaterials 2017, 122, 114-129.

(42) Xue, N.; Sun, T.; Tsang, W. M.; Delgado-Martinez, I.; Lee, S.H.; Sheshadri, S.; Xiang, Z.; Merugu, S.; Gu, Y.; Yen, S.-C.; Thakor, N. V. Sens. Actuators, B 2015, 210, 640-648.

(43) Rios, G.; Lubenov, E. V.; Chi, D.; Roukes, M. L.; Siapas, A. G. Nano Lett. 2016, 16, 6857-6862.

(44) Zimmermann, M. Science 1968, 160, 896-898.

(45) Llewellyn, M. E.; Thompson, K. R.; Deisseroth, K.; Delp, S. L. Nat. Med. 2010, 16, 1161-1165.

(46) Lewicki, M. S. Network: Comput. Neural Syst. 1998, 9, R53R78.

(47) Schmitzer-Torbert, N.; Jackson, J.; Henze, D.; Harris, K.; Redish, A. D. Neuroscience 2005, 131, 1-11.

(48) Jackson, A.; Fetz, E. E. J. Neurophysiol. 2007, 98, 3109-3118.

(49) Fu, T. M.; Hong, G.; Zhou, T.; Schuhmann, T. G.; Viveros, R. D.; Lieber, C. M. Nat. Methods 2016, 13, 875-882.

(50) Hong, G.; Lieber, C. M. Nat. Rev. Neurosci. 2019, 20, 330-345.

(51) Bignami, A.; Eng, L. F.; Dahl, D.; Uyeda, C. T. Brain Res. 1972, 43, 429-435.

(52) Xie, C.; Liu, J.; Fu, T.-M.; Dai, X.; Zhou, W.; Lieber, C. M. Nat. Mater. 2015, 14, 1286-1292.

(53) Zhou, T.; Hong, G.; Fu, T.-M.; Yang, X.; Schuhmann, T. G.; Viveros, R. D.; Lieber, C. M. Proc. Natl. Acad. Sci. U. S. A. 2017, 114, 5894-5899.

(54) Vollmers, K.; Frutiger, D. R.; Kratochvil, B. E.; Nelson, B. J. Appl. Phys. Lett. 2008, 92, 144103.

(55) Kummer, M. P.; Abbott, J. J.; Kratochvil, B. E.; Borer, R.; Sengul, A.; Nelson, B. J. IEEE T. Robot. 2010, 26, 1006-1017.

(56) Dryg, I. D.; Ward, M. P.; Qing, K. Y.; Mei, H.; Schaffer, J. E.; Irazoqui, P. P. IEEE T. Neur. Sys. Reh. 2015, 23, 562-571.

(57) Diller, E.; Giltinan, J.; Lum, G. Z.; Ye, Z.; Sitti, M. Int. J. Robot. Res. 2016, 35, 114-128.

(58) Chen, X.-Z.; Hoop, M.; Mushtaq, F.; Siringil, E.; Hu, C.; Nelson, B. J.; Pané, S. Appl. Mater. Today 2017, 9, 37-48. 